\title{
Oviposition Cues for a Specialist Butterfly-Plant Chemistry and Size
}

\author{
J. H. Reudler Talsma • A. Biere • J. A. Harvey • \\ S. van Nouhuys
}

Received: 20 February 2008 /Revised: 2 June 2008 /Accepted: 12 June 2008 /Published online: 9 July 2008

(C) The Author(s) 2008

\begin{abstract}
The oviposition choice of an insect herbivore is based on a complex set of stimuli and responses. In this study, we examined the effect of plant secondary chemistry (the iridoid glycosides aucubin and catalpol) and aspects of size of the plant Plantago lanceolata, on the oviposition behavior of the specialist butterfly Melitaea cinxia. Iridoid glycosides are known to deter feeding or decrease the growth rate of generalist insect herbivores, but can act as oviposition cues and feeding stimulants for specialized herbivores. In a previous observational study of $M$. cinxia in the field, oviposition was associated with high levels of aucubin. However, this association could have been the cause (butterfly choice) or consequence (plant induction) of oviposition. We conducted a set of dual- and multiplechoice experiments in cages and in the field. In the cages,
\end{abstract}

J. H. Reudler Talsma $(\bowtie) \cdot$ A. Biere $\cdot$ J. A. Harvey

Department of Multitrophic Interactions,

Netherlands Institute of Ecology, NIOO-KNAW,

Boterhoeksestraat 48, Postbox 40, 6666 ZG Heteren,

The Netherlands

e-mail: talsma.reudler@bytl.jyu.fi

S. van Nouhuys

Department of Biological and Environmental Sciences,

University of Helsinki,

P.O. Box 65, 00014 Helsinki, Finland

S. van Nouhuys

Department of Ecology \& Evolutionary Biology,

Cornell University,

Corson Hall,

Ithaca, NY 14853, USA

Present address:

J. H. Reudler Talsma

Department of Biological and Environmental Science, University of Jyväskylä,

P.O. Box 35, 40014 Jyväskylä, Finland we found a positive association between the pre-oviposition level of aucubin and the number of ovipositions. The association reflects the butterfly oviposition selection rather than plant induction that follows oviposition. Our results also suggest a threshold concentration below which females do not distinguish between levels of iridoid glycosides. In the field, the size of the plant appeared to be a more important stimulus than iridoid glycoside content, with bigger plants receiving more oviposition than smaller plants, regardless of their secondary chemistry. Our results illustrate that the rank of a cue used for oviposition may be dependent on environmental context.

Keywords Herbivore - Iridoid glycosides - Melitaea cinxia . Oviposition $\cdot$ Plantago lanceolata $\cdot$ Plant size

\section{Introduction}

Choosing a plant for oviposition is a challenging task for female herbivorous insects because site and plant selection are crucial for the successful development of her progeny (Singer 1986; Mayhew 1997). Ovipositing insects experience external stimuli (e.g., visual and olfactory cues), their own internal physiological stimuli, and a series of environmental constraints (e.g., availability of host plants; Visser 1986; Bernays and Chapman 1994; Badenes et al. 2004). In this paper, we study the role of plant secondary chemistry and size of the host plant Plantago lanceolata L. (Plantaginaceae) on the oviposition behavior of its specialist herbivore, the Glanville fritillary butterfly Melitaea cinxia (Linnaeus 1758) (Lepidoptera: Nymphalidae). Most lepidopteran species, 90-95\% (Stamp 1980; Hebert 1983), lay only a single egg on a plant before moving on to another plant and laying another egg. By contrast, checkerspot 
butterflies such as $M$. cinxia lay their eggs in clusters, often depositing a single cluster in a day (Wahlberg et al. 2004; Saastamoinen 2007). Butterflies that lay eggs singly must often seek at least 20-50 oviposition sites per day and thus may be more time limited than egg limited (Courtney 1982), whereas for butterflies that lay their eggs in clusters, the costs of prolonged search or host assessments may be beneficial (Singer 2004).

In general, butterflies are attracted to alight on plants through a combination of visual and olfactory stimuli (Rausher 1978; Feeny et al. 1989; Janz and Nylin 1997). A positive response to visual stimuli is to alight and taste a plant. To assess whether a plant is chemically acceptable, a female checkerspot butterfly scratches the surface of a leaf with the first pair of tarsal claws. This scratching damages the leaf surface and facilitates the release of chemical stimuli that are assessed by the female butterfly. If the plant is accepted for oviposition, the butterfly curls her abdomen to the underside of a leaf and oviposits. In checkerspot butterflies, plant acceptance depends on the physical features of the oviposition site such as the size, shape, and orientation of the leaf (Singer 2004).

Most checkerspot species are oligophagous or even monophagous on plant species that produce iridoid glycosides (IGs) as plant secondary compounds (Bowers 1983; Jensen 1991; Wahlberg 2001; Murphy et al. 2004; Reudler Talsma et al. 2008). In this study, we focus on two IGs, aucubin and catalpol, which are found in more than ten Asteridae plant families (El-Naggar and Beal 1980; Olmstead et al. 2000). These IGs are known to be oviposition cues for the specialist butterfly Junonia coenia (Pereyra and Bowers 1988) and feeding stimulants for larvae of at least some checkerspot butterflies (Bowers 1983). M. cinxia larvae perform better on diets high in iridoid glycosides (Harvey et al. 2005; Saastamoinen et al. 2007).

Nieminen et al. (2003) examined the natural pattern of oviposition by $M$. cinxia on their food plant, $P$. lanceolata in the field. The authors compared plants used for oviposition with neighboring and random plants in the patch. They found that plants used for oviposition contained significantly higher concentrations of aucubin than neighboring and random plants. Additionally, plants selected for oviposition and random plants had higher catalpol concentrations than neighboring plants. This suggests that ovipositing females selected plants with higher IG concentrations, or at least with higher concentrations of aucubin.

An alternative explanation for the positive association between IG concentrations and oviposition in Nieminen et al. (2003) is that the presence of butterfly eggs on leaf tissues leads to an induction of IGs in the plant. Studies of other insects have reported that allelochemicals in plants can be induced through oviposition and the presence of eggs on, or imbedded in, the leaf surface (Agrawal 2000; Colazza et al. 2004; Hilker et al. 2005). Induction of IGs by $M$. cinxia oviposition has not been investigated thus far, but IG production in $P$. lanceolata can be induced both by fungal infection (Marak et al. 2002) and by herbivory (Darrow and Bowers 1999; Stamp and Bowers 2000). Furthermore, Peñuelas et al. (2006) found that the leaves of Lonicera implexa (Camprifoliaceae) with egg clusters of Euphydryas aurinia (a close relative of M. cinxia) had 15fold higher concentrations of IGs than leaves directly opposite on the same plant.

Plant size as well as chemistry may influence butterfly oviposition choice. Large plants may receive more eggs than small plants simply because they are visually conspicuous and difficult to leave accidentally after alighting. If the butterfly can perceive size, then large plants may also be used because they are more suitable for larval development. For instance, the gregarious $M$. cinxia larvae seldom move to another individual plant during early instars (although this can happen, see "Results"), so they would benefit from a large oviposition plant (Kuussaari et al. 2004). Indeed, Nieminen et al. (2003) found that naturally occurring egg clusters tended to occur on larger than average plants. More generally, the 'plant vigor hypotheses', elaborated by Price (1991), predicts that vigorous pants that reach a larger than average size should be preferred by herbivores. Both plant biomass and nutritional quality may be higher in vigorous plants (Heisswolf et al. 2005; Lastra et al. 2006).

We performed a set of dual- and multiple-choice experiments in cages and in the field to answer the following questions: (1) What is the effect of $P$. lanceolata plant chemistry on the oviposition behavior of $M$. cinxia? (2) Does oviposition cause induction of IGs in the host plant? (3) What is the effect of plant size (measured as number of leaves) on the oviposition behavior of $M$. cinxia butterflies?

\section{Methods and materials}

Study Species M. cinxia (Glanville fritillary) butterflies used for these experiments were the offspring of fieldcaught butterflies from Åland, SW Finland. In Åland, the butterflies fly in June and lay large clusters (150-200 eggs) on the underside of leaves of P. lanceolata and Veronica spicata L. (Plantaginaceae) (Kuussaari et al. 2000). Larvae hatch after 2-4 weeks depending on the temperature. The larvae spin a communal web on the host plant and feed gregariously throughout the summer. Because of restricted mobility, small larvae usually depend on the host plant the adult female chose for oviposition. Larvae diapause gregariously as L5 in a silk winter nest and become active 
again in spring. In the last instar (L7), larvae disperse and feed individually. They pupate within the vegetation in mid May (Kuussaari et al. 2004).

$P$. lanceolata (ribwort plantain) is a perennial plant with a worldwide distribution (Sagar and Harper 1964). In natural populations, IG levels range from undetectable to ca. 9\% of dry weight (Bowers 1991). In the field in Åland, these concentrations range between $0.6 \%$ and $2.2 \%$ for aucubin and between $0.7 \%$ and $2.0 \%$ for catalpol (Nieminen et al. 2003). The variation in the constitutive IG amount in $P$. lanceolata is partially genetically determined (Adler et al. 1995; Bowers and Stamp 1992, 1993). Most plants used for oviposition experiments were derived from an artificial selection experiment, in which plants were selected on the basis of high and low concentrations of total leaf iridoid glycosides for four generations (Marak et al. 2000). For experiment 1 (see below), nine plants, each derived from a different half sib family from the low selection line, and six plants, each derived from a different half sib family from the high selection line, were clonally propagated following root cloning (Wu and Antonovics 1975). This resulted in 15 different genotypes. In addition, for experiments 2 and 3, five new crosses were made between pairs of plants of the low selection line and five crosses between pairs of plants of the high selection line. From each of these crosses, a single offspring was raised and clonally propagated. This resulted in five from the low (L1-L5) and five genotypes originating from the high (H1-H5) IG selection line. Since not all genotypes originating from the high selection line have higher IG concentrations than all genotypes originating from the low selection line under all environmental conditions (see "Results"), we use differences in IG between genotypes, rather than selection lines, as the basis of our experiments. In experiment 1 , we included 15 more plants that were collected from the field in Åland to extend the range of variation in concentrations of aucubin and catalpol used in the experiment. Although these plants had similar IG concentrations as genotypes from the selection lines (field plants $4.3 \pm 0.5 \%$ dry weight (dw); plants from the selection lines $4.5 \pm 0.5 \% \mathrm{dw}$ ), they had lower average concentrations of aucubin but higher average concentrations of catalpol (see Fig. 4).

Oviposition Experiments Three experiments were carried out to study the oviposition behavior of $M$. cinxia in response to concentrations of iridoid glycosides and plant size of $P$. lanceolata. In experiments 1 and 2, we offered potted plants to butterflies in cages by using dual (exp. 1) or multiple (exp. 2) choice tests. In experiment 3, we transplanted plants and butterflies to a natural field plot. Experiments were carried out in Finland, except for one of the cage experiments (exp. 2) that was carried out in the Netherlands. In the cage experiments, none of the plants flowered, and M. cinxia females usually laid a single egg batch per plant.

Experiment 1: Small Cages, Finland In total, 30 pairs of plants were used in dual-choice oviposition tests, using eight small mesh cages $(38 \times 38 \times 44 \mathrm{~cm})$ over the course of 13 days in June 2005 , when the weather was sunny and warm. Cages were placed outside the Nåtö Biological Station, Åland, Finland. In 18 trials, we used sets of two $P$. lanceolata plants of different genotypes, one randomly selected from the nine genotypes of the low, and one randomly selected from the six genotypes of the high selection line. In 12 other trials, we used sets of two of the Finnish plants from the field. Before the plants were put in the cage, we counted the number of leaves, and the second fully expanded leaf was taken to determine its IG content by using high-performance liquid chromatography (HPLC) analyses. A mated female $M$. cinxia butterfly was put into each cage along with a sponge saturated with honey water (1:3) to provide a source of water and food for the butterfly. At the end of the day, all plants and butterflies were removed from the cages. Plants were then searched for butterfly egg clusters. The following day, the number of eggs in each cluster was counted. This process was repeated with new plants and butterflies without oviposition experience. If a butterfly died in the cage, and there was no oviposition, the same pair of plants was used again with a new butterfly. In total, 44 different female butterflies were used, and 19 of them oviposited.

To see if there was systemic induction of IGs in the plant after oviposition, we determined the IG concentrations in leaves from 28 plants that received eggs (19 from experiment 1 and an additional nine from a similar unpublished experiment). We compared the IG concentration of the second fully expanded leaf, sampled before oviposition, with that of a leaf from the same rosette ring as the one that bore the egg batch. This leaf was sampled the evening after oviposition.

Statistical Analyses Cage trial was used as the experimental unit. In 19 of the cages, oviposition was observed. In 17 cases, butterflies oviposited on only one of the two plants. In two cases, butterflies oviposited on both plants, but laid a "normal-sized" cluster on one plant (overall clutch size \pm $\mathrm{SE}=121 \pm 22$ ) and only a few eggs (18 and 23, respectively) on the other plant. Only plants with the "normal-sized" clusters were considered as oviposition plants in the analyses. Paired $t$ tests (STATISTICA version 7.1 (StatSoft Inc., Tulsa, OK, USA) were used to test whether within a cage leaf IG concentrations and plant size (number of leaves) differed between plants with and without oviposition. The number of leaves, the number of eggs, and the aucubin concentration were $\log 10$-transformed prior to 
analyses to meet the assumptions of normality and homogeneity of variances. We used Pearson's correlations to test for associations of egg cluster size with the iridoid concentrations and plant size (number of leaves).

Experiment 2: Large Cages, the Netherlands Ten cages $(1 \times 1 \times 1 \mathrm{~m})$ were placed outside near the Netherlands Institute of Ecology at Heteren. In each cage, we placed ten plants, five genotypes originating from the low (L1-L5) and five originating from the high IG selection line (H1H5; see study species). Each cage represented a single replicate. We counted the number of leaves on each plant and collected the sixth fully expanded leaf for chemical analyses. A male and female of $M$. cinxia were released into each cage. Over the following days, we checked for evidence of oviposition, but if oviposition occurred, we did not remove the plant or the butterflies. We marked the leaves onto which the female butterflies had oviposited, but did not remove the eggs. If a female died without ovipositing, she was replaced by a new female. The experiment was terminated when all of the butterflies had died. In total, we used 13 female butterflies from 25th May until the 16th June 2003, six of these butterflies laid eggs.

Statistical Analyses Cages were used as the experimental unit. Paired $t$ tests were used to test whether average IG concentrations and the number of leaves differed between plants with and without oviposition events within a cage. Aucubin was $\log 10$-transformed, and catalpol and total IG values were square-root-transformed prior to analyses to meet assumptions of normality and homogeneity of variances. Associations of plant size with iridoid concentration were compared by using Pearson's correlations.

\section{Experiment 3: Uncaged Field Experiment, Finland We} used the same ten genotypes of $P$. lanceolata as in the above experiment, L1-L5 and H1-H5. In the fall of 2001, we made 40 clonal replicates of each genotype by using the root-cloning method from $\mathrm{Wu}$ and Antonovics (1975). Plants were maintained over the winter in $11 \mathrm{~cm}$ pots filled with potting soil in an unheated greenhouse in Heteren, the Netherlands. In May 2002, roots of the ca. 25-cm tall plants were washed to remove adhering potting soil, put in moist bags, shipped to Finland, and stored at $4{ }^{\circ} \mathrm{C}$ until transplantation. A small field was selected as transplantation site, in an open, dry rocky area on peat soil with sparse shrubs and trees near Tvärminne Zoological Station, SW Finland (59 $\left.50^{\prime} 35 \mathrm{~N}, 23^{\circ} 14^{\prime} 54 \mathrm{E}\right)$. This site represents a suitable habitat within the distribution range of $P$. lanceolata and $M$. cinxia, but neither of the species was present. On May 11, 2002, plants were planted in 40 patches of ten plants, with each patch containing one individual of each genotype. Roots were gently placed in small slits in the soil to minimize disturbance of the natural vegetation. Plants within the patches were planted $10 \mathrm{~cm}$ apart, and the patches were at least $2 \mathrm{~m}$ apart. They were watered as required.

M. cinxia larvae were collected from Åland in 2001, overwintered as fifth instar in the lab at Nåtö Biological Station, Finland, and pupated in the spring of 2002.

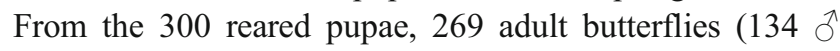
and 135 P) emerged, and were introduced in the field site the morning after they had emerged. This occurred between June 6 and 9, 2002, when the experimental plants had regrown new leaves under the prevailing conditions.

We harvested the two youngest fully expanded leaves of each plant from seven patches and air-dried them for HPLC analysis of IGs to estimate the average concentration of IGs for each genotype in the field. Starting when the first butterflies were released on June 6, plants were checked daily for the presence of egg clusters. Egg clusters were left in place and we recorded whether eggs hatched and whether caterpillars managed to produce a winter nest. As some caterpillars moved from the oviposition plant to nearby plants, the number of damaged plants exceeded the number of plants on which oviposition occurred, and some winter nests occurred on non-oviposition plants. On June 15 , we measured the number of leaves and the length and width of the longest leaf of each experimental plant. All plants in the field were of the same age because they were cloned at the same time.

Statistical Analyses Differences in plant size and iridoid glycoside concentrations among genotypes and patches were analyzed by using generalized linear models (Procedure GENMOD, SAS v. 8.2, SAS Institute, Cary, NC, USA) with a normal error distribution. Leaf length, leaf width, leaf number, and the product of these ("plant size index"), as well as the concentrations of aucubin, catalpol, and total IG were square-root-transformed prior to analyses to meet assumptions of normality and homogeneity of variance. Plant size index was used as a covariate in analyses of iridoid glycosides to estimate size-independent genotypic differences in secondary chemistry. Effects of plant size, genotype, and patch on the number of egg clusters, number of hatched clusters, and number of diapausing clusters per plant were analyzed by using a GLM with a Poisson error distribution and a log-link function after $(x+1)$ transformation of the independent variables. Since concentrations of aucubin and catalpol were measured only in a subset of the plants and yielded insufficient data on phenotypic associations between secondary metabolites and oviposition, the effects of aucubin and catalpol on oviposition were assessed by using the mean genotypic concentration. We performed univariate and multiple regression of genotype means for size and secondary metabolite concentrations on genotype 
means for oviposition traits (number of egg clusters laid, hatched, and surviving to diapause).

Chemical Analyses The second fully expanded leaf was taken from all the P. lanceolata plants used in experiment 1 . They were air-dried in open envelopes as were the leaves collected from the field plot in experiment 3 . The sixth fully expanded leaf from the plants in the cages in Heteren (exp. 2) were frozen at $-80^{\circ} \mathrm{C}$ and freeze-dried. After the leaf drying step, the procedure for chemical analyses was the same for all experiments. Leaves were ground with a Laboratory Vibration Mill (MM 301, Retsch GmBH \& Co, Germany). Fine ground dry material of the leaves $(25 \mathrm{mg})$ was extracted in $10 \mathrm{ml}$ of $70 \% \mathrm{MeOH}$ and shaken overnight. The crude extract was filtered on a Whatman \#4 filter paper and diluted ten times with Milli-Q water. Concentrations of the IGs aucubin and catalpol were analyzed by HPLC with a Bio-Lc (Dionex Corp., Sunnyvale, CA, USA) equipped with a GP40 gradient pump, a Carbopac PA 1 guard $(4 \times 50 \mathrm{~mm})$ and analytical column $(4 \times 250 \mathrm{~mm})$, and an ED40 electrochemical detector for pulsed amperimetric detection (PAD). $\mathrm{NaOH}(1 \mathrm{M})$ and Milli-Q water were used as eluents $(10: 90,1 \mathrm{ml} / \mathrm{min})$. Retention times were 3.25 and $4.40 \mathrm{~min}$ for aucubin and catalpol, respectively. Concentrations were analyzed with Chromeleon version 6.60 (Dionex Corp. Sunnyvale, CA, USA).

\section{Results}

Experiment 1: Small Cages, Finland Oviposition was observed in 19 cages, with a total of 21 egg batches. Plants onto which $M$. cinxia oviposited had a significantly higher level of aucubin $(2.56 \pm 0.43)$ than plants without $(1.57 \pm$ 0.37 ) oviposition within the same cage (paired $t$ test, $t=$ $2.78, d f=16, P=0.013$; Fig. 1a). In $71 \%$ of the cases, females chose the plant with the higher aucubin concentration. By contrast, there were no consistent differences in the concentration of catalpol between plants selected (2.25 \pm $0.35)$ and ignored $(2.59 \pm 0.35)$ for oviposition (paired $t$ test, $t=-0.72, d f=16, P=0.48$ ). There was also no significant difference in the total IG concentration between plants with $(4.81 \pm 0.58)$ and without $(4.16 \pm 0.55)$ oviposition (paired $t$ test, $t=0.81, d f=16, P=0.43)$.

The number of leaves on the plants ranged from six to 26. There was no association of leaf number with oviposition choice (paired $t$ test, $t=0.45, d f=15, P=0.66$; Fig. 1b). In $43 \%$ of the cases, the plant onto which the butterfly oviposited had fewer leaves than the alternative plant, whereas in $50 \%$ of the cases it had more leaves. For plants on which eggs were laid, there was no correlation between the egg cluster size and the iridoid concentration

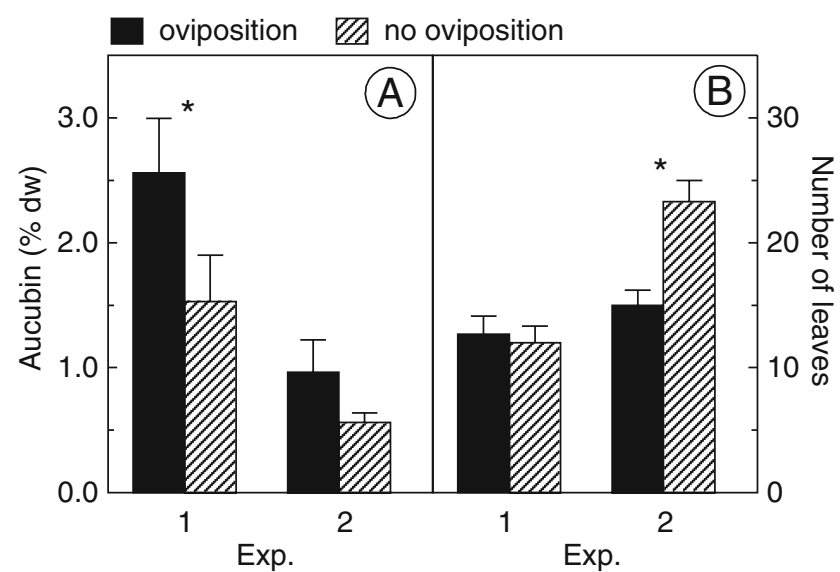

Fig. 1 a Average leaf concentration of aucubin (percent of dry weight) and $\mathbf{b}$ average number of leaves on Plantago lanceolata plants with (black bars) and without (hatched bars) oviposition by Melitaea cinxia in experiments 1 and 2 . Note that experiment 1 represents a 1day dual-choice test, whereas experiment 2 represents a multiplechoice test of longer duration. See text for a detailed description of the experiments. ${ }^{*} P<0.05$

or plant size (number of leaves; aucubin: $r=-0.085, N=17$, $P=0.75$; catalpol: $r=0.15, N=17, P=0.56$; total iridoid level: $r=0.19, N=17, P=0.46$; no. of leaves: $r=0.43, N=16$, $P=0.10$ ).

The observed patterns of associations between plant traits and oviposition did not differ between the cages with plants originating from the field (Finnish plants) and the cages with plants from the cloned Dutch genotypes. Higher concentrations of aucubin in plants chosen for oviposition were observed both for the Finnish $(1.8 \pm 0.6 \%$ vs. $1.0 \pm$ $0.3 \%)$ and for the Dutch plants $(3.3 \pm 0.6 \%$ vs. $2.0 \pm 0.6 \%)$, whereas neither the concentration of catalpol (Finnish: $3.0 \%$ vs. $3.4 \%$; Dutch $1.6 \%$ vs. $1.7 \%$ ) nor the number of leaves (Finnish 17.4 vs. 15.3; Dutch 9.4 vs. 9.0) affected oviposition.

We analyzed concentrations of iridoid glycosides in leaves of 28 plants both before and after oviposition. These measures did not differ significantly, suggesting that there was no systemic induction of IGs by the oviposition event within the observed time frame ( 1 day; paired $t$ test, aucubin: $t=-0.15, d f=27, P=0.89$; catalpol: $t=0.22, d f=27$, $P=0.82$; total iridoid glycosides: $t=1.7, d f=27, P=0.10$ ).

Experiment 2: Large Cages, the Netherlands Oviposition by $M$. cinxia was observed in six of the ten cages, on one to four plants within a cage, with a total of 15 egg batches on 12 plants. The average iridoid glycoside concentrations of plants with oviposition did not differ from those without oviposition within a cage (paired $t$ tests, aucubin: $t=1.35$, $d f=5, P=0.23$; Fig. 1a; catalpol: $t=1.83, d f=5, P=0.13$; total IG concentration: $t=1.57, d f=5, P=0.18$ ). Egg batches 
were found on plants with significantly fewer leaves than average $(t=-3.91, d f=5, P<0.05$; Fig. $1 \mathrm{~b})$. The number of leaves ranged from six to 49 and was negatively correlated with the iridoid concentration (aucubin: $r=-0.047, N=59$, $P<0.001$; catalpol: $r=-0.045, N=59, P<0.001$; total IG level: $r=-0.048, N=59, P<0.001)$.

Experiment 3: Field Site, Finland; Size and Chemistry of Plant Genotypes Plant size differed both among genotypes and patches (Tables 1 and 2). There was a three-fold variation among genotypes. Genotypes also showed a significant, ca. four-fold, variation in their average leaf concentration of iridoid glycosides (Table 1). The range of aucubin concentrations (nine-fold) was larger than the range of catalpol concentrations (four-fold, Table 1). Although genotypes originating from the high IG selection line (H1-H5) on average had higher concentrations of total iridoid glycosides than genotypes originating from the low IG selection line (L1-L5; Table 1), the concentrations of the constituent components aucubin and catalpol varied greatly among genotypes within lines. Part of the variation in total concentrations of iridoid glycosides and catalpol among plants was associated with plant size (Table 2). The total IG concentration of the plant was negatively correlated with both the number of leaves and the size index of the plants (phenotype concentration: no. of leaves: $r=-0.55, N=64$, $P<0.001$; size index: $r=-0.43, N=64, P<0.001$; genotype concentration: no. of leaves: $r=-0.77, N=10, P<0.01$; size index: $r=-0.68, N=10, P<0.05)$. In other words, larger plants tended to have lower IGs. The concentrations of both aucubin and catalpol were independent of the patch where plants were growing (Table 2).
Experiment 3: Field Site, Finland; Oviposition and Performance of M. cinxia on Different Plant Genotypes Egg clusters of M. cinxia were found in $41(10.3 \%)$ plants in the field site. The total number of egg clusters was 63 , with a maximum of seven per plant and nine per patch. Forty-eight (76.2\%) of the egg clusters hatched, and one-third of them eventually produced winter nests. Of these nests, 13 were on the initial oviposition plant and eight on non-oviposition plants to which the larvae had moved during the season.

The number of egg clusters per plant increased significantly with plant size and differed both among patches and among genotypes (Table 3), ranging from a mean number of 0.025 to 0.50 clusters per plant for different genotypes. Similar effects were found for the number of successful clusters, i.e., clusters that hatched (Table 3). The effects of plant size on the number of egg clusters were mainly due to an increase in oviposition with the number of leaves per plant (Fig. 2a). The association between maximum leaf length and oviposition was non-linear: plants with leaves of an intermediate length of ca. $8 \mathrm{~cm}$ were the most often used for oviposition (Fig. 2b), whereas leaf width was not associated with the number of egg clusters on a plant $(P>$ 0.5 ). Univariate regression analysis (Table 4) showed that at the genotype level, two factors significantly contributed to differences in the number of egg clusters per plant: average concentrations of aucubin and average leaf length (Table 4, Fig. 2b,c). In a multiple regression, the effect of aucubin disappeared (Table 4), indicating that it was partly mediated by genotypic correlations with other factors. In particular, this involved a negative correlation with leaf number (Fig. 3) that tended to have a positive effect on oviposition (Fig. 2a), and a positive correlation with maximum leaf

Table 1 Characteristics of ten Plantago lanceolata genotypes selected for low (L1-L5) or high (H1-H5) leaf IG in the Tvärminne field site and occurrence of Melitaea cinxia on them (exp. 3)

\begin{tabular}{|c|c|c|c|c|c|c|c|c|c|c|c|c|c|c|}
\hline & \multicolumn{6}{|c|}{ Leaf IG (\% dw) } & \multicolumn{4}{|c|}{ Plant size $(\mathrm{cm})$} & \multicolumn{4}{|c|}{ M. cinxia } \\
\hline & Total & SE & Aucubin & SE & Catalpol & SE & Size index & Leaf number & Leaf length & Leaf width & $\mathrm{P}$ & $\mathrm{C}$ & $\mathrm{H}$ & \\
\hline L1 & $2.15^{\mathrm{a}}$ & 0.11 & $0.55^{\mathrm{a}}$ & 0.05 & $1.57^{\mathrm{a}}$ & 0.09 & $179.0^{\mathrm{f}}$ & $17.9^{\mathrm{c}}$ & $10.2^{\mathrm{ab}}$ & $0.99^{\mathrm{bc}}$ & 11 & 20 & 17 & \\
\hline L2 & $5.77^{\mathrm{bc}}$ & 0.19 & $1.98^{\mathrm{cd}}$ & 0.11 & $3.77^{\mathrm{bc}}$ & 0.15 & $89.6^{\mathrm{bc}}$ & $6.2^{\mathrm{a}}$ & $13.4^{\mathrm{c}}$ & $1.03^{\mathrm{c}}$ & 1 & 1 & 1 & \\
\hline L3 & $5.79^{\mathrm{bc}}$ & .018 & $2.93^{\mathrm{d}}$ & 0.12 & $2.80^{\mathrm{b}}$ & 0.12 & $95.9^{\text {bcd }}$ & $9.7^{\mathrm{b}}$ & $11.8^{\mathrm{bc}}$ & $0.85^{\mathrm{ab}}$ & 3 & 3 & 3 & \\
\hline L4 & $5.30^{\mathrm{b}}$ & 0.19 & $2.62^{\mathrm{cd}}$ & 0.12 & $2.67^{\mathrm{b}}$ & 0.13 & $101.1^{\text {cde }}$ & $7.7^{\mathrm{ab}}$ & $9.7^{\mathrm{a}}$ & $1.34^{\mathrm{d}}$ & 5 & 5 & 1 & \\
\hline L5 & $6.29^{\mathrm{bcd}}$ & 0.20 & $0.85^{\mathrm{ab}}$ & 0.07 & $5.41^{\mathrm{d}}$ & 0.18 & $64.9^{\mathrm{ab}}$ & $9.8^{\mathrm{b}}$ & $9.4^{\mathrm{a}}$ & $0.70^{\mathrm{a}}$ & 3 & 4 & 4 & \\
\hline $\mathrm{H} 1$ & $7.27^{\text {cde }}$ & 0.20 & $1.85^{\mathrm{c}}$ & 0.09 & $5.39^{\mathrm{d}}$ & 0.17 & $125.3^{\mathrm{de}}$ & $9.8^{\mathrm{b}}$ & $12.0^{\mathrm{bc}}$ & $1.03^{\mathrm{c}}$ & 3 & 3 & 3 & \\
\hline $\mathrm{H} 2$ & $8.60^{\mathrm{e}}$ & 0.22 & $4.93^{\mathrm{e}}$ & 0.15 & $3.65^{\mathrm{bc}}$ & 0.14 & $90.1^{\mathrm{bcd}}$ & $7.0^{\mathrm{a}}$ & $13.0^{\mathrm{c}}$ & $0.97^{\mathrm{bc}}$ & 1 & 1 & 1 & \\
\hline H3 & $7.91^{\mathrm{de}}$ & 0.23 & $1.62^{\mathrm{bc}}$ & 0.10 & $6.20^{\mathrm{d}}$ & 0.20 & $83.5^{\mathrm{abc}}$ & $8.0^{\mathrm{ab}}$ & $10.5^{\mathrm{ab}}$ & $0.98^{\mathrm{bc}}$ & 4 & 10 & 9 & \\
\hline $\mathrm{H} 4$ & $6.65^{\text {bcde }}$ & 0.23 & $2.00^{\mathrm{cd}}$ & 0.12 & $4.51^{\mathrm{cd}}$ & 0.19 & $56.0^{\mathrm{a}}$ & $6.0^{\mathrm{a}}$ & $9.0^{\mathrm{a}}$ & $0.93^{\mathrm{bc}}$ & 7 & 12 & 8 & \\
\hline H5 & $5.07^{\mathrm{b}}$ & 0.17 & $1.72^{\mathrm{c}}$ & 0.09 & $3.32^{\mathrm{bc}}$ & 0.13 & $138.9^{\mathrm{ef}}$ & $9.2^{\mathrm{b}}$ & $13.8^{\mathrm{c}}$ & $1.07^{\mathrm{c}}$ & 3 & 4 & 1 & \\
\hline
\end{tabular}

Values for leaf IG concentrations and plant size are back-transformed least square estimates from GLM with block and genotype effects. Values within columns that do not share a common letter have non-overlapping $95 \%$ confidence intervals. Occurrence of $M$. cinxia is summed over the 40 replicate plants per genotype: the observed numbers of plants with egg clusters $(\mathrm{P})$, total numbers of egg clusters $(\mathrm{C})$, hatched clusters $(\mathrm{H})$, and diapausing groups in winter nests (D). 
Table 2 Effects of patch and genotype on the size and leaf IG concentration of Plantago lanceolata in the Tvärminne field site (exp. 3)

\begin{tabular}{|c|c|c|c|c|c|c|c|c|c|}
\hline Source & $d f$ & Size index & Leaf number & Leaf length & Leaf width & $d f$ & IG total & Aucubin & Catalpol \\
\hline Covariate & & & & & & 1 & $35.3 * * *$ & 3.0 & $30.9 * * *$ \\
\hline Patch & 39 & $2.5 * * *$ & $2.5 * * *$ & $1.9^{* *}$ & $2.5 * * *$ & 7 & 1.3 & 1.1 & 1.6 \\
\hline Genotype & 9 & $12.0^{* * *}$ & $22.9^{* * *}$ & $10.9^{*}$ & $11.5^{* * *}$ & 9 & $12.9^{* * *}$ & $13.5^{* * *}$ & $10.1 * * *$ \\
\hline Error & 334 & & & & & 49 & & & \\
\hline
\end{tabular}

Size index was used as a covariate in analyses of IGs. Values are quasi- $F$ values from GLM analyses of deviance.

$* P<0.05 ; * * P<0.01 ; * * * P<0.001$

length that had a negative effect on oviposition in the range of values for the genotype means (Fig. 2b).

Comparison of Plant Chemistry Between the Three Experiments The total amount of IGs as well as the ratio of aucubin to catalpol differed among the experiments (Fig. 4). Plants originating from Finnish field sites that were used in the small cages (exp. 1) and cloned genotypes transplanted into natural habitat in Finland (exp. 3) had on average more catalpol than aucubin. By contrast, cloned genotypes grown in potting soil in the small cages in Finland (exp. 1) or large cages in the Netherlands (exp. 2) had on average more aucubin than catalpol. In the large cage experiment (exp. 2), the concentrations of IGs were generally very low. Especially striking is the huge difference between the plants used for the experiment in NL (exp. 2) and the field experiment in Finland (exp. 3) because plants used for these two experiments were of the same genotypes. Although the rank order of the genotypes was consistent across both of these experiments (Fig. 5), the absolute concentrations of IGs were significantly higher in the field experiment in Finland (exp. 3). Concentrations of aucubin in these genotypes were ca. three times higher in Finland $(t=5.44, d f=9, P<0.001)$, whereas concentrations of catalpol were on average more than 20 times higher in the field experiment in Finland (4.0\%) than in the large cage experiment in the Netherlands $(0.16 \% ; t=8.75, d f=9$, $P<0.001)$

Table 3 Effects of plant size, patch, and genotype of Plantago lanceolata in the Tvärminne field site (exp. 3) on the number of oviposited and the number of hatched Melitaea cinxia egg clusters per plant

\begin{tabular}{lrrr}
\hline & $d f$ & Egg clusters & Hatched \\
\hline Plant size & 1 & $45.6^{* * *}$ & $56.5^{* * *}$ \\
Patch & 39 & $2.3^{* * *}$ & $2.2^{* * *}$ \\
Genotype & 9 & $5.1^{* * *}$ & $5.4^{* * *}$ \\
Error & 333 & & \\
\hline
\end{tabular}

Values are quasi- $F$ values from GLM analyses of deviance.

$* * * P<0.001$

\section{Discussion}

Butterflies that lay eggs in clusters, such as checkerspots, are expected to spend more time discriminating among potentially suitable host plants than solitary egg laying species (Singer 2004). When a searching M. cinxia female alights on a plant, it habitually "tastes" it, rests for a while before moving to another part of the plant or to another plant, and tastes again, continuing this process until she finds a plant chemically acceptable and begins to oviposit. The female selects where to oviposit based on cues she obtains from the plant. The results of the cage experiment in Finland (exp. 1) suggest that oviposition choice in female butterflies is related to concentration of aucubin in the plant. This result is in agreement with those of Nieminen et al. (2003) obtained by sampling from natural populations in the field.

We found no difference in IG concentrations of leaves before and after oviposition, suggesting that the butterflies chose plants with higher aucubin, and that the oviposition event itself did not systemically induce further production of IGs. However, since we did not measure IG concentrations before and after oviposition in the leaf that was actually oviposited on, there remains the possibility that local induction in the leaf selected for oviposition occurs (Peñuelas et al. 2006). Also, our post-oviposition sample occurred the evening after oviposition. It is possible that the induction of the IGs took longer than a single day. Unfortunately, although induction of secondary metabolites following herbivory is well studied, the timing of induction that follows oviposition is poorly studied. We do know that induction of IGs in $P$. lanceolata that follows fungal infection has been observed as early as $6 \mathrm{~h}$ after inoculation (Marak et al. 2002), while induction after leaf damage by caterpillars of the specialist $J$. coenia was not observed until 6 days after herbivory (Fuchs and Bowers 2004).

The concentration of aucubin is correlated with the total concentration of IGs. Several experiments have shown that the performance of $M$. cinxia larvae is enhanced when the larvae feed on plants with a higher concentration of IGs than on plants with a lower concentration. They have a shorter development time, higher larval weight, and they 

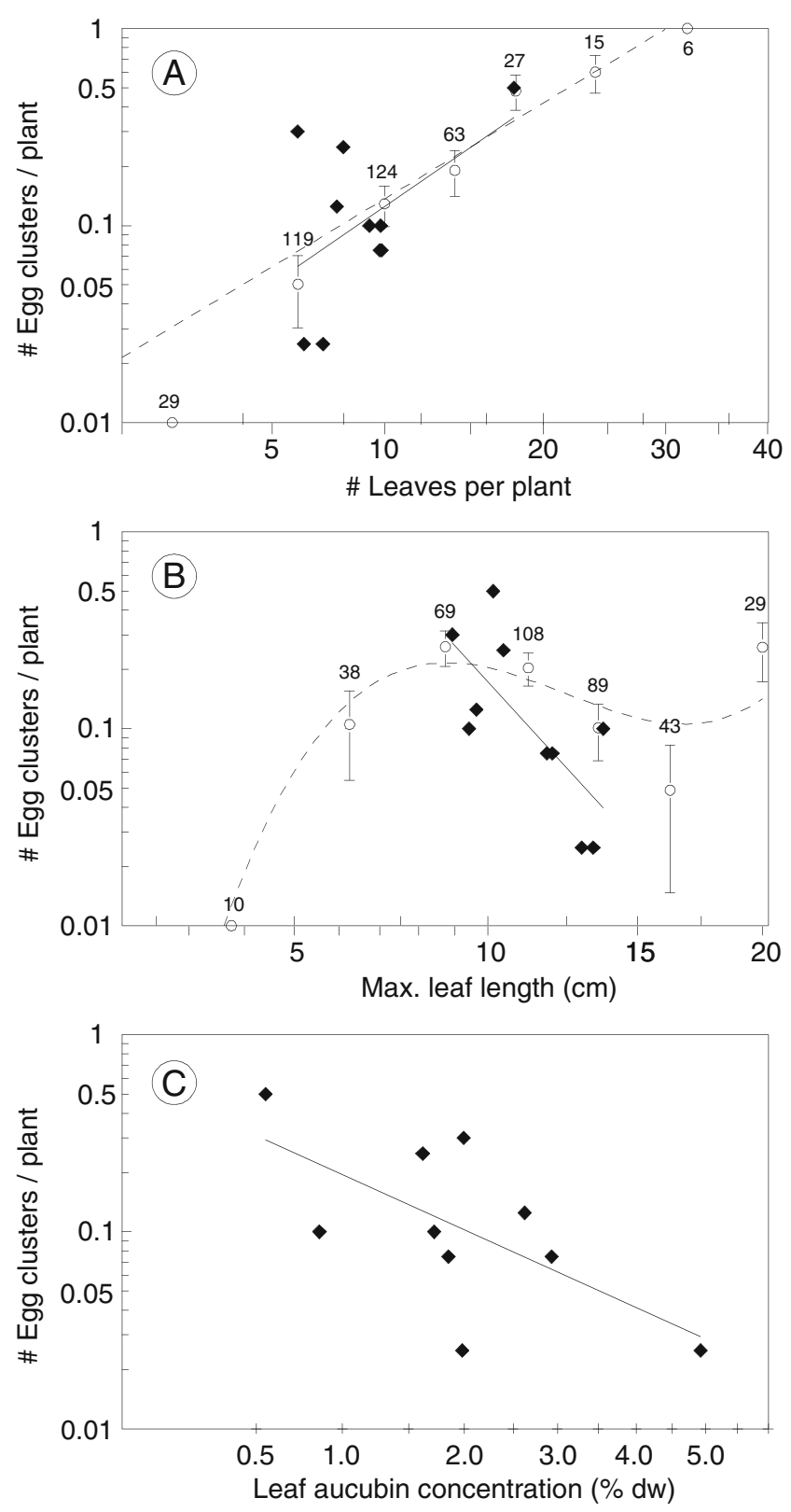

Fig. 2 Number of Melitaea cinxia egg clusters ( $Y$-axis log scale) per Plantago lanceolata plant in experiment 3, as a function of a number of leaves per plant, b length of the longest leaf per plant, and $\mathbf{c}$ leaf aucubin concentration ( $X$-axis, square root scale). Black diamonds represent genotype mean values of traits with corresponding solid lines of regression. Open circles (sample size on top) represent mean numbers of egg clusters for classes of phenotypic values of leaf number and leaf length \pm 1 SE (class limits indicated above the $X$ axis). Dotted lines are corresponding polynomial regression lines based on parameter estimates from Poisson regressions of the phenotypic data

tend to have a larger pupal size (Harvey et al. 2005; Saastamoinen et al. 2007). These trait values are usually associated with a higher fitness (Roff 1992). There are many factors that affect larval fitness of $M$. cinxia, but larval size is strongly correlated with overwintering
Table 4 Univariate and multiple regressions of genotype means for morphological and chemical traits on genotype means for the number of Melitaea cinxia egg clusters per plant of Plantago lanceolata in the Tvärminne field site (exp. 3)

\begin{tabular}{lll}
\hline & Univariate & Multivariate \\
\hline Total IGs & -0.503 & - \\
Aucubin & $-0.648^{*}$ & -0.231 \\
Catalpol & -0.140 & - \\
Plant size index & +0.199 & - \\
No. of leaves per plant & +0.503 & +0.278 \\
Max. leaf length & $-0.718^{*}$ & $-0.583^{+}$ \\
Max. leaf width & -0.005 & - \\
Model $R^{2}$ & & $0.71^{*}$ \\
\hline
\end{tabular}

Values are standardized regression coefficients.

${ }^{+} P<0.10 ; * P<0.05$

survival, which can be low (Nieminen et al. 2001; Kuussaari et al. 2004). The shorter development time also may be an advantage for $M$. cinxia because of the short growing season (Kuussaari et al. 2004). Furthermore, fast development decreases the period of time the caterpillar will be vulnerable to its natural enemies (Benrey and Denno 1997; van Nouhuys and Lei 2004).

Another advantage of feeding on plants with a high concentration of iridoid glycosides may be chemical defense against predators and parasitoids. Specialized larvae feeding on iridoid-producing plants are able to sequester these iridoids and become distasteful or noxious to their natural enemies (Bowers 1980, 1981, 1990; Bowers and Puttick 1986; Gardner and Stermitz 1988; L'Empereur and Stermitz 1990; Stermitz et al. 1994; Camara 1997; Nieminen et al. 2003).

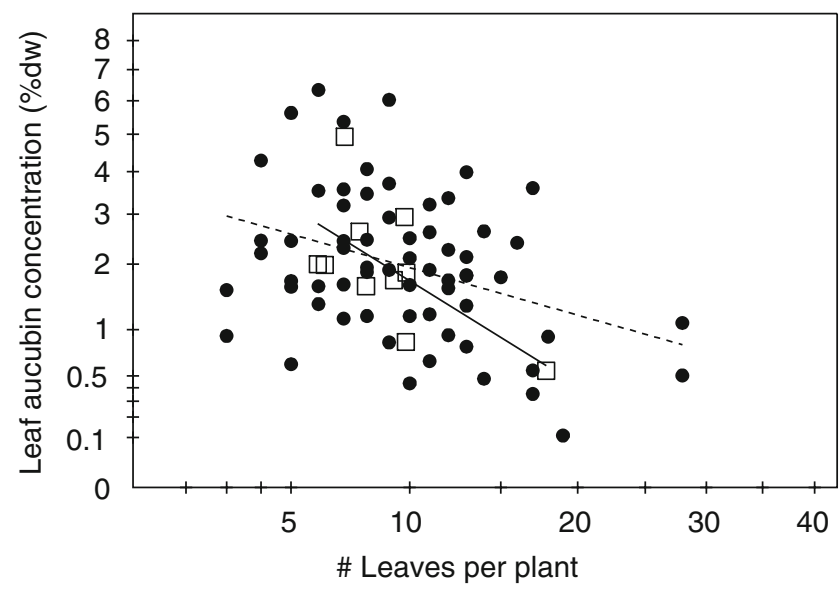

Fig. 3 Regression of phenotypic values (black dots, dotted line) and genotype means (open squares, solid line) of leaf aucubin concentration on the number of leaves per Plantago lanceolata plant in experiment 3 


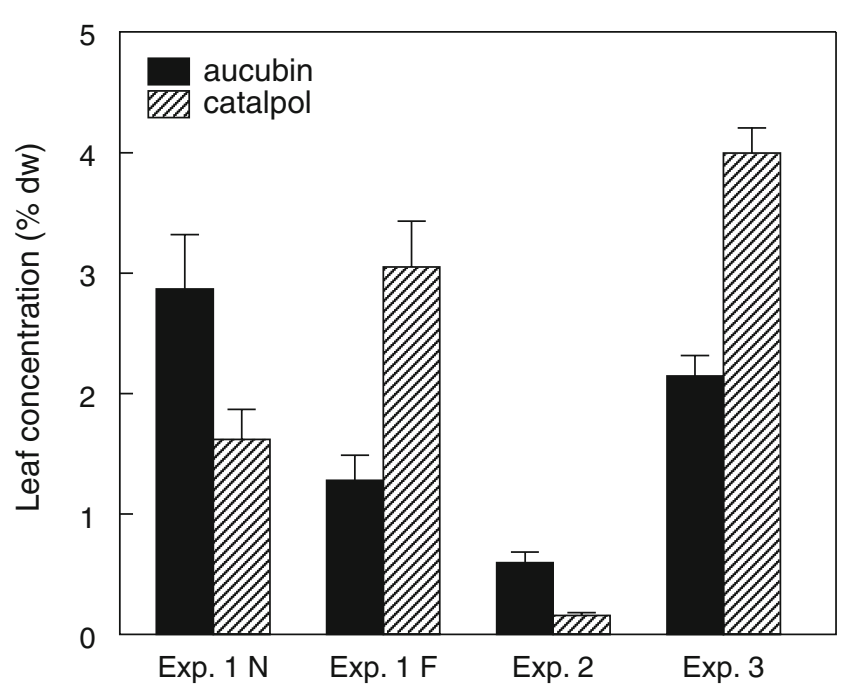

Fig. 4 Mean aucubin and catalpol concentration of Plantago lanceolata plants used in the three experiments. Black bars indicate the mean aucubin concentration, hatched bars the mean catalpol concentration. Exp. $1 \mathrm{~N}$ : small cages, Finland (Dutch genotypes); exp. 1 F: small cages, Finland (Finnish plants); exp. 2: large cage, the Netherlands; exp. 3: field site, Finland. See text for a detailed description of the different experiments

The fact that we did not observe an association of oviposition choice with IGs in experiment 2 (large cages NL) could be because of the overall low concentration of IGs in these plants. Perhaps, the female $M$. cinxia is not able to discriminate at such low absolute amounts of IGs (on average lower than $1 \%$ of the dry weight). This would suggest a threshold concentration below which these secondary metabolites are no longer used as a suitable cue for oviposition decisions although the small sample size of six females also could have contributed to the lack of a significant relationship.

The results of the field experiment (exp. 3) differed from the results of the cage studies. Perhaps, this is not surprising. In the field, $M$. cinxia and other checkerspots visit many possible plants without ovipositing, and the ranking of plants can depend on time and context (Schöps and Hanski 2001; Singer 2004). Thus, the plants used in the field should probably be considered a more absolute choice than in the cages where the butterflies may have selected plants that they would reject in other circumstances. Notably, the size of the plant (mainly the number of leaves per plant) had a positive effect on the oviposition preference of the females in the field, while in the cage experiment there was no association (exp. 1) or a significantly negative association (exp. 2) between these parameters. As mentioned, the higher oviposition rates of M. cinxia on larger plants in the field are in agreement with observations in natural populations by Nieminen et al. (2003). This is not unexpected given the limited mobility of early instar gregarious caterpillars (Kuussaari et al. 2004).
A further possible explanation for the stronger impact of plant size on oviposition in the field than in cage experiments is the different range of plant sizes between the field and cage studies. In the field, the difference in leaf number between the smallest and largest plant was 78; in the cage study in Finland, the mean difference in leaf number between the plants between which $M$. cinxia could choose was only 3.3. Because of this smaller variation in plant size in the cage experiments, the oviposition choice of the female in the cages could be based to a greater extent on chemical rather than visual stimuli. In addition, the use of visual cues may manifest more clearly in the field experiment where butterflies may encounter plants at a distance, whereas in the cages they are constrained in close proximity to each plant.

Future studies are needed to disentangle the relative importance of plant size and IG concentrations of individual plants for oviposition in the field. In the cage experiments, IGs were measured for each individual plant. Associations between oviposition and traits including IGs could be studied at the individual plant level. However, in the field experiment (exp. 3), IG concentrations were measured for a subset of plants only. Based on these measurements, genotype mean IG concentrations were used to assess associations between oviposition and IGs. This resulted in a loss of power to detect associations and reduced our ability do distinguish effects of morphological traits from IGs on oviposition.

In summary, our results show that ovipositing $M$. cinxia discriminate between host plants based at least on factors associated with plant chemistry and size. For females in the field experiment, the size of the plant was a positive stimulus, whereas in the cages, where plants were more

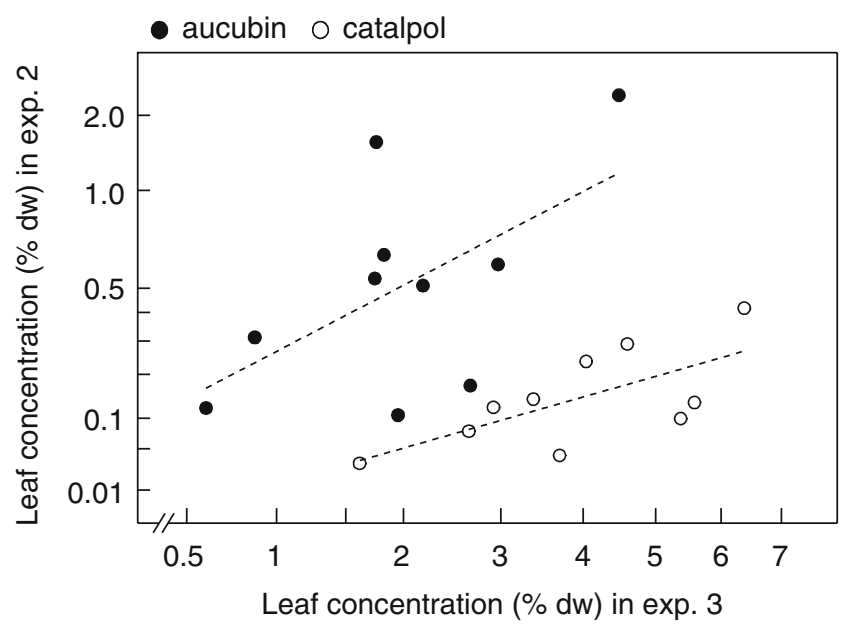

Fig. 5 Average leaf concentrations of aucubin (black dots) and catalpol (open dots) of ten Plantago lanceolata genotypes used in experiment 2 vs. the average IG concentrations of the same genotypes in experiment 3 . See text for a detailed description of the experiments 
similar in size and appearance, chemical stimuli were apparently more important. In particular, oviposition tended to increase with constitutive concentration of aucubin.

Acknowledgments We thank two anonymous reviewers for helpful comments on this manuscript, and H. Paulomaki, K. Linqvist, K. Luodekari, and K. Valosaari for field and laboratory assistance. The Tvärminne Zoological Station and Nåtö Biological Station provided facilities in Finland. This study was supported by a grant from the Earth and Life Science Foundation (ALW) of the Netherlands Organisation for Scientific Research (NWO) and the Academic Academy of Finland Centre of excellence grant no. 20286. This is NIOO publication no. 4298.

Open Access This article is distributed under the terms of the Creative Commons Attribution Noncommercial License which permits any noncommercial use, distribution, and reproduction in any medium, provided the original author(s) and source are credited.

\section{References}

ADLER, L. S., SCHMITT, J., and Bowers, M. D. 1995. Genetic-variation in defensive chemistry in Plantago lanceolata (Plantaginaceae) and its effect on the specialist herbivore Junonia coenia (Nymphalidae). Oecologia 101:75-85.

Agrawal, A. A. 2000. Plant defense: signals in insect eggs. Trends Ecol. Evol. 15:357.

Badenes, F., Shelton, A., and Nault, B. 2004. Evaluating trap crops for diamondback moth, Plutella xylostella (Lepidoptera: Plutellidae). J. Econ. Entomol. 97:1365-1372.

BENREY, B., and DENNO, R. F. 1997. The slow-growth-high-mortality hypothesis: a test using the cabbage butterfly. Ecology 78:987999.

Bernays, E. A., and Chapman, R. F. 1994. Host-Plant Selection by Phytophagous Insects. Chapman and Hall, New York.

Bowers, M. D. 1980. Unpalatability as a defense strategy of Euphydryas phaeton (Lepidoptera: Nymphalidae). Evolution 34:586-600.

BOWERS, M. D. 1981. Unpalatability as a defense strategy of western checkerspot butterflies (Euphydryas, Nymphalidae). Evolution 35:367-375.

BOWERS, M. D. 1983. The role of iridoid glycosides in host-plant specificity of checkerspot butterflies. J. Chem. Ecol. 9:475-793.

BOWERS, M. D. 1990. Recycling plant natural products for insect defense, pp. 353-386, in D. L. Evans, and J. O. Schmidt (eds.). Insect Defenses: Adaptive Mechanisms and Strategies of Prey and PredatorsState University of New York Press, Albany.

Bowers, M. D. 1991. Iridoid glycosides, pp. 297-325, in G. A. Rosenthal, and M. R. Berenbaum (eds.). Herbivores: Their Interactions with Secondary Plant MetabolitesAcademic, San Diego.

Bowers, M. D., and PutTick, G. M. 1986. Fate of ingested iridoid glycosides in Lepidopteran herbivores. J. Chem. Ecol. 12:169178.

Bowers, M. D., and STAMP, N. E. 1992. Chemical variation within and between individuals of Plantago lanceolata (Plantaginaceae). J. Chem. Ecol. 18:985-995.

Bowers, M. D., and STAMP, N. E. 1993. Effects of plant-age, genotype, and herbivory on Plantago performance and chemistry. Ecology 74:1778-1791.

CAMARA, M. D. 1997. Predator responses to sequestered plant toxins in buckeye caterpillars: are tritrophic interactions locally variable? J. Chem. Ecol. 23:2093-2106.
Colazza, S., Fucarino, A., Peri, E., Salerno, G., Gonti, E., and BIN, F. 2004. Insect oviposition induces volatile emission in herbaceous plants that attracts egg parasitoids. J. Exp. Biol. 207:47-53.

COURTNEY, S. P. 1982. Coevolution of pierid butterflies, and their cruciferous foodplants. IV. Crucifer apparency and Anthocharis cardamines oviposition. Oecologia 52:258-265.

DARROW, K., and BOWERS, M. D. 1999. Effects of herbivore damage and nutrient level on induction of iridoid glycosides in Plantago lanceolata. J. Chem. Ecol. 25:1427-1440.

El-Naggar, L. J., and BeAL, J. L. 1980. Iridoids: a review. J. Nat. Prod. 43:649-707.

FeEny, P. P., Stadler, E., AhMan, I., and CARTER, M. 1989. Effects of plant odor on oviposition by the black swallowtail butterfly, Papilio polyxenes (Lepidoptera: Papilionidae). J. Insect Behav. 2:803-827.

Fuchs, A., and Bowers, M. D. 2004. Patterns of iridoid glycoside production and induction in Plantago lanceolata and the importance of plant age. J. Chem. Ecol. 30:1723-1741.

GARDNER, D. R., and STERMITZ, F. R. 1988. Host plant utilization and iridoid glycoside sequestration by Euphydryas anicia (Lepidoptera, Nymphalidae). J. Chem. Ecol. 14:2147-2168.

Harvey, J. A., van, NouhuYs, S., and BiERE, A. 2005. Effects of quantitative variation in allelochemicals in Plantago lanceolata on development of a generalist and a specialist herbivore and their endoparasitoids. J. Chem. Ecol. 31:287-302.

HeBERT, P. D. N. 1983. Egg dispersal patterns and adult feeding behavior in the Lepidoptera. Can. Entomol. 115:1477-1481.

Heisswolf, A., Obermaier, E., and PoethKe, H. J. 2005. Selection of large host plants for oviposition by a monophagous leaf beetle: nutritional quality or enemy-free space? Ecol. Entomol. 30:299306.

Hilker, M., Stein, C., Schröder, R., Varama, M., and Mumm, R. 2005. Insect egg deposition induced defence response in Pinus sylvestris. J. Exp. Biol. 208:1849-1854.

JANZ, N., and NYLIN, S. 1997. The role of female search behavior in determining host plant range in plant feeding insects: a test of the information processing hypothesis. Proc. R. Soc. B: Biol. Sci. 264:701-707.

JENSEN, S. R. 1991. Plant iridoids, their biosynthesis and distribution in angiosperms, pp. 133-158, in J. B. Harborne, and F. A. Tomas-Barberan (eds.). Ecological Chemistry and Biochemistry of Plant TerpenoidsClarendon, Oxford.

KUUSSAARI, M., SINGER, M., and HANSKI, I. 2000. Local specialization and landscape-level influence on host use in an herbivorous insect. Ecology 81:2177-2187.

KuUSSAari, M., van, NouhuYs, S., Hellmann, J., and Singer, M. 2004. Larval biology of checkerspots, pp. 138-160, in P. R. Ehrlich, and I. Hanski (eds.). On the Wings of Checkerspots: A Model System for Population BiologyUniversity Press, Oxford.

L'empereur, K. M., and Stermitz, F. R. 1990. Iridoid glycoside content of Euphydryas anicia (Lepidoptera: Nymphalidae) and its major host plant, Besseya plantaginea (Scophulariaceae), at high plains Colorado site. J. Chem. Ecol. 16:187-197.

Lastra, J. A. S., Barrios, L. E. G., Rojas, J. C., and Rivera, H. P. 2006. Host selection behavior of Leptophobia aripa (Lepidoptera: Pieridae). Fla. Entomol. 89:127-134.

MaraK, H. B., Biere, A., and van, Damme, J. M. M. 2000. Direct and correlated responses to selection on iridoid glycosides in Plantago lanceolata L. J. Evol. Biol. 13:985-996.

Marak, H. B., Biere, A., and van, Damme, J. M. M. 2002. Systemic, genotype-specific induction of two herbivore-deterrent iridoid glycosides in Plantago lanceolata L. in response to fungal infection by Diaporthe adunca (Rob.) Niessel. J. Chem. Ecol. 28:2429-2448. 
MAYHEW, P. J. 1997. Adaptive patterns of host-plant selection by phytophagous insects. Oikos 79:417-428.

MurPHY, D. D., WAHLBERG, N., HANSKI, I., and EHRLICH, P. R. 2004. Introducing checkerspots: taxonomy and ecology, pp. 17-33, in P. R. Ehrlich, and I. Hanski (eds.). On the Wings of Checkerspots: A Model System for Population BiologyOxford University Press, Oxford.

NiEMINEN, M., Singer, M., Fortelius, W., SCHÖPS, K., and HANSKI, I. 2001. Experimental confirmation that inbreeding depression increases extinction risk in butterfly populations. Am. Nat. 157:237-244.

Nieminen, M., S, uomi, J., van, NouhuYs, S., SAURI, P., and RIEKKOLA, M. L. 2003. Effect of iridoid glycoside content on oviposition host plant choice and parasitism in a specialist herbivore. J. Chem. Ecol. 29:823-844.

OlmStEAD, R. G., Kim, K. J., JanSEN, R. K., and WagstafF, S. J. 2000. The phylogeny of the Asteridae sensu latu based on chloroplast $n d h \mathrm{~F}$ gene sequences. Mol. Phylogenet. Evol. 16:96-112.

Peñuelas, J., Sardans, J., Stefanescu, C., Parella, T., and FILLELLA, I. 2006. Lonicera implexa leaves bearing naturally laid eggs of the specialist herbivore Euphydryas aurinia have dramatically greater concentrations of iridoid glycosides than other leaves. J. Chem. Ecol. 32:1925-1933.

Pereyra, P. C., and Bowers, M. D. 1988. Iridoid glycosides as oviposition stimulants for the buckeye butterfly, Junonia coenia (Nymphalidae). J. Chem. Ecol. 14:917-928.

PRICE, P. W. 1991. The plant vigour hypothesis and herbivore attack. Oikos 62:244-492.

RAUSHER, M. D. 1978. Search image for leaf shape in a butterfly. Science 200:1071-1073.

Reudler, TAlsma, J. H., TORRI, K., and van, NouhuYs, S. 2008. Host plant use by the Heath fritillary butterfly, Melitaea athalia: plant habitat, species and chemistry. Arthropod-Plant Interact 2:63-75.

Roff, D. A. 1992. The Evolution of Life Histories. Chapman and Hall, New York.

SAASTAMOINEN, M. 2007. Life-history, genotypic and environmental correlates of clutch size in the Glanville fritillary butterfly. Ecol. Entomol. 32:235-242.

SaAstamoinen, M., van, Nouhuys, S., Nieminen, M., O'hara, B., and SuOMI, J. 2007. Development and survival of a specialist herbivore, Melitaea cinxia, on host plants producing high and low concentrations of iridoid glycosides. Ann. Zool. Fenn. 44:70-80.

SAGAR, G. R., and HARPER, J. L. 1964. Biological flora of the British isles. Plantago major L., Plantago media L. and Plantago lanceolata L. J. Ecol. 52:189-221.

SCHÖPS, K., and HANSKI, I. 2001. Population level correlation between pre-alighting and post-alighting host plant preference in the Glanville fritillary butterfly. Ecol. Entomol. 26:517-524.

SINGER, M. C. 1986. The definition and measurement of oviposition preference in plant-feeding insects, pp. 65-94, in J. R. Miller, and M. A. Miller (eds.). Insect-Plant InteractionsSpringer, New York.

SINGER, M. C. 2004. Measurement, correlates, and importance of oviposition preference in the life of checkerspots, pp. 112-137, in P. R. Ehrlich, and I. Hanski (eds.). On the Wings of Checkerspots: A Model System for Population BiologyOxford University Press, Oxford.

STAMP, N. E. 1980. Egg deposition patterns in butterflies: why do some species cluster their eggs rather than deposit them singly? Am. Nat. 115:367-380.

Stamp, N. E., and Bowers, M. D. 2000. Do enemies of herbivores influence plant growth and chemistry? Evidence from a seminatural experiment. J. Chem. Ecol. 26:2367-2386.

Stermitz, F. R., Kader, M. S. A., Foderaro, T. A., and Pomeroy, M. 1994. Iridoid glycosides from some butterflies and their larval food plants. Phytochemistry 37:997-999.

van, NouhuYs, S., and LeI, G. C. 2004. Parasitoid and host metapopulation dynamics: the influences of temperature mediated phenological asynchrony. J. Anim. Ecol. 73:526-535.

VISSER, J. 1986. Host odor perception in phytophagous insects. Annu. Rev. Entomol. 31:121-144.

WAHLBERG, N. 2001. The phylogenetics and biochemistry of hostplant specialization in Melitaeine butterflies (Lepidoptera: Nymphalidae). Evolution 55:522-537.

WAhlberG, N., Ehrlich, P. R., BoggS, C. L., and HANSKI, I. 2004. Bay checkerspot and Glanville fritillary compared with other species, pp. 219-244, in P. R. Ehrlich, and I. Hanski (eds.). On the Wings of Checkerspots: A Model System for Population BiologyOxford University Press, Oxford.

WU, L., and ANTONOVICS, J. 1975. Experimental ecological genetics in Plantago. I. Induction of roots and shoots on leaves for large scale vegetative propagation and metal tolerance testing in $P$. lanceolata. New Phytol. 75:277-282. 